\title{
Erratum to: Calcium vitamin D3 supplementation in clinical practice: side effect and satisfaction
}

\author{
Maryam Sanaei ${ }^{1}$, Mohammad Banasiri $^{2}$, Gita Shafiee$^{1}$, Mahsa Rostami $^{1}$, Saba Alizad ${ }^{1}$, Mehdi Ebrahimi $^{3}$, \\ Bagher Larijani ${ }^{3}$ and Ramin Heshmat ${ }^{1 *}$
}

\section{Erratum}

This article [1] was unintentionally published twice in this journal, by the same authors. The following should be considered the version of record and used for citation purposes: "Sanaei et al., Calcium vitamin D3 supplementation in clinical practice: side effect and satisfaction, Journal of Diabetes \& Metabolic Disorders (2016) 15:5, 10.1186/ s40200-016-0227-9". The duplicate "Sanaei et al., Calcium vitamin D3 supplementation in clinical practice: side effect and satisfaction, Journal of Diabetes \& Metabolic Disorders (2016) 15:9, 10.1186/s40200-016-0231-0" is to be ignored. Editor-in-Chief Prof Bagher Larijani apologizes to the readers of the journal for not detecting the duplication during the publication process.

\footnotetext{
Author details

${ }^{1}$ Chronic Diseases Research Center, Endocrinology and Metabolism

Population Sciences Institute, Tehran University of Medical Sciences, \# 111, 19th St, North Kargar Ave, Tehran, Iran. ${ }^{2}$ Orthopaedic surgery Department, Medical school, Golestan University of Medical Sciences, Tehran, Iran. ${ }^{3}$ Endocrinology and Metabolism Research Center, Endocrinology and Metabolism Research Institute, Tehran University of Medical Sciences, Tehran, Iran.
}

Received: 13 September 2017 Accepted: 13 September 2017

Published online: 18 September 2017

\section{Reference}
1. Sanaei, et al. Calcium vitamin D3 supplementation in clinical practice: side effect and satisfaction. J Diabetes Metab Disord. 2016;15:5. doi:10.1186/s40200-016-0227-9.

\footnotetext{
* Correspondence: rheshmat@tums.ac.ir

${ }^{1}$ Chronic Diseases Research Center, Endocrinology and Metabolism

Population Sciences Institute, Tehran University of Medical Sciences, \# 111 ,

19th St, North Kargar Ave, Tehran, Iran

Full list of author information is available at the end of the article
} 